\title{
Fontes e doses de nitrogênio para mamoneira de porte baixo no sistema plantio direto
}

\author{
Nitrogen fertilizers and rates in castor bean hybrids under no-till system \\ Edemar Moro ${ }^{\mathrm{I}}$ Carlos Alexandre Costa Crusciol ${ }^{\mathrm{II}}$ Priscila de Oliveira ${ }^{\mathrm{II}}$ \\ Tainá Barcellos Sipos ${ }^{\mathrm{IV}}$
}

\section{RESUMO}

O cultivo de mamona em grandes áreas se tornou possível com a introdução recente de híbridos de porte baixo que possibilitam a mecanização total das práticas agrícolas, inclusive na colheita. No entanto, as informações sobre práticas agrícolas a serem empregadas, quando da utilização desses híbridos, ainda são escassas, principalmente, no que se refere ao manejo da adubação nitrogenada. O trabalho teve como objetivo estabelecer as doses de nitrogênio mais adequadas para híbridos de mamona de porte baixo no sistema plantio direto. $O$ experimento foi conduzido por dois anos agrícolas (2005/2006 e 2006/2007) na Fazenda Experimental Lageado, UNESP, Botucatu (SP). Os tratamentos foram constituídos por duas fontes de nitrogênio (sulfato de amônio e uréia) e por quatro doses $\left(0,30,60\right.$ e $120 \mathrm{~kg} \mathrm{ha}^{-1}$ de N) aplicadas em cobertura aos 20 dias após a emergência, sendo utilizado o híbrido Savana. A adubação nitrogenada de cobertura promoveu aumento de produtividade ao híbrido de mamona no sistema plantio direto. A produtividade de grãos não diferiu entre as fontes de $N$ utilizadas. A dose média de $N$ calculada que proporcionou a maior produtividade de grãos foi de $88 \mathrm{~kg} \mathrm{ha}^{-1}$ na safra 2005/2006 e 100kg ha-1 na safra 2006/2007.

Palavras-chave: Ricinus communis L., adubação nitrogenada, sistema de produção.

\section{ABSTRACT}

The castor bean crop in large areas has become possible with the recent introduction of short stature hybrids that allow the complete mecanization of agricultural practices, including the harvest. However, when hibrids are used, the information about agricultural practices to be employed, are still very poor, especially, with regard to management nitrogen fertilization. The aim of this study was to evaluate the effect of nitrogen sources and doses in castor bean hybrids under no-till system in summer crop. The experiment was conducted for two crop years (2005/2006 and 2006/2007). The experiment design was a randomized blocks in $2 \times 4$ factorial design with four replications. The treatments comprised the combination of two nitrogen sources (ammonium sulfate and urea), with four doses of nitrogen $\left(0,30,60\right.$ and $120 \mathrm{~kg} \mathrm{ha}^{-1}$ of $\left.\mathrm{N}\right)$ surface applied 20 days after emergence, plus a control. The hybrid Savana was utilized. The nitrogen fertilization increased productivity of the castor bean under no-till system. The grain yield wasn't influenced by the nitrogen source utilized. The average rate calculated that allowed the maximum grain yield was $88 \mathrm{~kg} \mathrm{ha}^{-1}$ in the 2005/2006 crops and 100kg ha $\mathrm{k}^{-1}$ in the 2006/2007 crops.

Key words: Ricinus communis L., nitrogen fertilization, production systems.

\section{INTRODUÇÃO}

A crescente demanda de fontes alternativas de energia impulsionou a produção de biodiesel no Brasil. O biodiesel pode ser feito a partir de qualquer óleo vegetal. Porém, o óleo da mamona destaca-se por ser mais denso e viscoso (BELTRÃO, 2003). Em

IUniversidade do Oeste Paulista (UNOESTE), Rodovia Raposo Tavares, Km 572, Campus II, Bloco B3, 19067-175, Presidente Prudente, SP, Brasil. E-mail: edemar@unoeste.br. Autor para correspondência.

IDepartamento de Produção Vegetal (Agricultura), Faculdade de Ciências Agronômicas (FCA), Universidade Estadual Paulista (UNESP), Campus de Botucatu, Botucatu, SP, Brasil.

IIIEmbrapa Cerrados, Planaltina, DF, Brasil.

${ }^{\text {Iv }}$ Syngenta Crop Protection, Uberlândia, MG, Brasil. 
decorrência da demanda de matéria prima para a produção de biodiesel, foram desenvolvidas pesquisas para melhorar a produtividade da mamoneira. A partir dessas pesquisas, surgiram os híbridos com as seguintes características: potencial produtivo, precocidade, amadurecimento uniforme, baixa deiscência, alto teor de óleo, resistência a pragas e doenças e porte baixo adequados à colheita mecanizada (AZEVEDO et al., 2001).

A adaptação à colheita mecanizada e o aumento do potencial produtivo possibilitou o cultivo da mamoneira em grandes áreas e sua inserção no sistema plantio direto (SPD). No SPD, a disponibilidade de $\mathrm{N}$ é menor e, dessa forma, as recomendações de adubação nitrogenada existentes para cultivares tradicionais em sistema convencional de preparo de solo não podem ser aplicadas aos novos materiais. No Estado de São Paulo, recomendava-se para as cultivares $15 \mathrm{~kg} \mathrm{ha}^{-1}$ de $\mathrm{N}$ na semeadura e doses que variam de $30 \mathrm{a}$ $60 \mathrm{~kg} \mathrm{ha}^{-1}$ de $\mathrm{N}$ em cobertura, aplicadas entre 30 a 40 dias após a emergência (SAVY FILHO, 1997).

Como é recente a introdução de híbridos de mamoneira em programas de rotação de culturas, temse carência de técnicas de cultivo. Assim, o manejo da adubação nitrogenada em híbridos de porte baixo, com elevado potencial produtivo, tanto para o cultivo na safra quanto na safrinha, é praticamente desconhecido, principalmente no SPD. Nessas condições, pode ocorrer menor disponibilidade de nitrogênio para as plantas (HEINRICHS et al., 2001), principalmente quando o cultivo é realizado após gramíneas. Segundo FAGERIA et al. (1999), a eficiência de utilização das fontes de $\mathrm{N}$ mais empregadas no Brasil é baixa, ao redor de $50 \%$. Além disso, o nitrogênio é o nutriente mais exportado pela mamona e o segundo mais extraído (NAKAGAWA, 1971). Segundo SANTOS et al. (2004), quando a mamona foi cultivada sob deficiência de nitrogênio, ocorreu redução no crescimento. A frutificação, quando ocorreu, foi fraca com poucos racemos e frutos com peso abaixo do esperado.

Outro aspecto que deve ser considerado é a diferença entre o custo e aproveitamento das fontes de $\mathrm{N}$. O custo por unidade de $\mathrm{N}(\mathrm{kg})$ do sulfato de amônio é 25\% superior a uréia. Em condições tropicais, quando as condições climáticas forem desfavoráveis, podem ocorrer perdas expressivas de $\mathrm{N}$ por meio da volatilização. Para a fonte uréia, perdas por volatilização de até $30,3 \%$ do $\mathrm{N}$ aplicado são comuns. Para o sulfato de amônio, as perdas são praticamente nulas, frequentemente menores que $1 \%$ do nitrogênio aplicado(ANJOS \& TEDESCO, 1976).

Considerando a baixa eficiência das fontes nitrogenadas e a alta demanda da cultura em $\mathrm{N}$, as doses recomendadas para cultivares tradicionais podem não ser suficientes para que os híbridos expressem seu potencial produtivo, principalmente quando cultivados no sistema plantio direto. $\mathrm{O}$ trabalho teve como objetivo estabelecer as doses de nitrogênio mais adequadas para híbridos de mamona de porte baixo no sistema plantio direto.

\section{MATERIAL E MÉTODOS}

O experimento foi conduzido por dois anos agrícolas (2005/2006 e 2006/2007) na Fazenda Experimental Lageado, UNESP, Botucatu (SP), a $48^{\circ}$ $23^{\prime} \mathrm{W}, 22^{\circ} 51^{\prime} \mathrm{S}$ e $740 \mathrm{~m}$ de altitude, em um Latossolo Vermelho distroférrico (EMBRAPA, 2006). As características químicas do solo na camada arável (020cm) foram: safra 2005/2006 $\mathrm{pHCaCl}_{2}(1: 2,5) 5,1 ; 24 \mathrm{~g}$ $\mathrm{dm}^{-3}$ de M.O.; $16 \mathrm{mg} \mathrm{dm}^{-3}$ de P (resina); 1,5; 31; 17; $38 \mathrm{mmol}_{\mathrm{c}} \mathrm{dm}^{-3} \mathrm{de} \mathrm{K}, \mathrm{Ca}, \mathrm{Mg}$ e acidez total $\mathrm{pH} 7.0(\mathrm{H}+\mathrm{Al})$, respectivamente, e $56 \%$ de saturação de bases. Safra 2006/2007 $\mathrm{pHCaCl}_{2}(1: 2,5)$ 5,2; $40 \mathrm{~g} \mathrm{dm}^{-3}$ de M.O. ; $21 \mathrm{mg}$ $\mathrm{dm}^{-3}$ de P (resina); 2,4; 23; 14; 44mmol $\mathrm{dm}^{-3}$ de K, Ca, $\mathrm{Mg}$ e acidez total $\mathrm{pH} 7.0(\mathrm{H}+\mathrm{Al})$, respectivamente, e $47 \%$ de saturação de bases.

O delineamento experimental foi em blocos casualizados, com quatro repetições, em esquema fatorial $2 \times 4$. Os tratamentos foram constituídos pela combinação de duas fontes de nitrogênio (sulfato de amônio e uréia) com quatro doses de nitrogênio $(0,30$, 60 e $120 \mathrm{~kg} \mathrm{ha}^{-1}$ de N), aplicadas em cobertura aos 20 dias após a emergência (DAE), sendo utilizado o híbrido Savana. As doses foram definidas com base na recomendação de SAVY FILHO (1997) para a cultura da mamona, cujas quantidades de $\mathrm{N}$ em cobertura variam de 30 a $60 \mathrm{~kg} \mathrm{ha}^{-1}$. Assim, utilizou-se o dobro da maior dose recomendada, com objetivo de avaliar o potencial de produção, quando da utilização de híbrido de porte baixo.

As parcelas tinham $5 \mathrm{~m}$ de largura e 5 metros de comprimento, perfazendo uma área total de $25 \mathrm{~m}^{2}$. O espaçamento foi $0,9 \mathrm{~m}$ entre linhas e a densidade e 25.000 plantas ha $\mathrm{h}^{-1}$. Cada unidade experimental continha seis fileiras de plantas. Para a adubação de base, aplicou-se $250 \mathrm{~kg} \mathrm{ha}^{-1}$ da formulação $08-28-16+4,5 \%$ de $\mathrm{S}+0,5 \%$ de $\mathrm{Zn}$, na safra 2005/2006, e 200kg ha-1 na safra 2006/2007.

A aplicação dos tratamentos foi realizada no estádio em que as plantas continham 4 a 5 folhas inteiramente abertas (20DAE). Foi realizada compensação do enxofre com gesso para igualar a quantidade de $\mathrm{S}$ aos tratamentos que receberam a dose máxima de SA.

Por ocasião do florescimento (45DAE), determinou-se a produção de massa seca da parte aérea 
das plantas, coletando-se 10 plantas por parcela. Também foram coletados 10 limbos da quarta folha, totalmente aberta a partir do ápice, os quais foram secados em estufa com circulação de ar a $60-70^{\circ} \mathrm{C}$, até atingir massa constante. $\mathrm{O}$ material seco foi utilizado para diagnose foliar e teores de $\mathrm{N}-\mathrm{NO}_{3}{ }^{-}$e N-NH${ }_{4}{ }^{+}$ (TEDESCO et al., 1985).

Os componentes da produção avaliados foram: população final de plantas; número de racemos/ planta; número de frutos/racemo; número de grãos/ fruto e peso de 100 grãos. Para determinação da produtividade, foram colhidas, em cada parcela, as plantas de duas linhas centrais de comprimento de $4 \mathrm{~m}$. Os racemos foram trilhados, os grãos pesados e a produtividade calculada em $\mathrm{kg} \mathrm{ha}^{-1}$ (a umidade foi corrigida para $8 \%$ ).

Os dados obtidos foram submetidos à análise de variância. Os efeitos entre as fontes de $\mathrm{N}$, dentro de cada dose do nutriente, foram analisados pelo teste $\mathrm{t}$ (LSD) a 5\%. Os efeitos entre doses de $\mathrm{N}$ dentro de cada fonte foram analisados por meio de análise de regressão. Sendo o teste $\mathrm{F}$ da variância da regressão significativo a $5 \%$, foram escolhidos os modelos, adotando-se, como critérios, o maior $\mathrm{R}^{2}$ e a adequação biológica. Quando não houve diferença entre sulfato de amônio e uréia, os dados apresentados representaram a média das duas fontes.

\section{RESULTADOS E DISCUSSÃO}

O teor foliar de $\mathrm{N}^{-} \mathrm{NO}_{3}{ }^{-}$em ambas as safras foram incrementados com a elevação das doses de $\mathrm{N}$, e os dados foram ajustados à função linear (Figura 1), no entanto, não houve diferenças entre as fontes (Tabela 1). Os teores de $\mathrm{N}-\mathrm{NH}_{4}{ }^{+}$não foram afetados pelas fontes e doses de $\mathrm{N}$ em ambas as safras (Tabela 1). PEUKE et al. (1996) observaram que, na mamoneira, a maior parte do $\mathrm{N}_{-} \mathrm{NO}_{3}{ }^{-}$é reduzido e assimilado nas raízes. Neste caso, os efeitos não ocorreram devido aos altos teores de $\mathrm{N}_{-} \mathrm{NO}_{3}{ }^{-}$no solo, antes da aplicação dos tratamentos. De acordo com D'ANDRÉA et al. (2004), nos sistemas com culturas anuais, principalmente no SPD, as concentrações de $\mathrm{N}_{-} \mathrm{NO}_{3}{ }^{-}$superam as de $\mathrm{N}^{-\mathrm{NH}_{4}}{ }^{+}$na camada superficial do solo.

Os teores de N-total tanto na safra 2005/ 2006, quanto na safra 2006/2007 (Figura 1) foram incrementados pelas doses de N. Na safra 2005/2006, os dados foram ajustados à função linear para ambas as fontes. $\mathrm{O}$ menor teor de nitrogênio para a fonte uréia pode ter ocorrido por perdas de $\mathrm{N}$ por volatilização. Segundo BARBOSA FILHO \& SILVA (2001), as perdas de $\mathrm{N}$ na forma de amônia podem ser elevadas quando a uréia é aplicada na superfície do solo no SPD. Na safra
2006/2007, o ajuste foi linear e não houve diferença entre as fontes. Em ambas as safras, os valores obtidos estavam acima da faixa adequada que é de $40-50 \mathrm{~g} \mathrm{~kg}^{-1}$ (MALAVOLTA et al. 1997). O menor valor no teor de nitrogênio em relação à safra 2005/2006 (Tabela 1) provavelmente ocorreu por efeito diluição, visto que a produção de matéria seca foi maior nesta (Figura 2).

Os teores foliares de $\mathrm{P}, \mathrm{Ca}$ e $\mathrm{Mg}$ não foram afetados pelas fontes e doses de $\mathrm{N}$ em ambas as safras (Tabela 1). Os teores de P na safra 2005/2006 estiveram dentro da faixa adequada e, na safra 2006/2007, abaixo do ideal ( $\left.3-4 \mathrm{~g} \mathrm{~kg}^{-1}\right)$. Os teores de Ca estiveram muito próximos à faixa adequada $\left(15-25 \mathrm{~g} \mathrm{~kg}^{-1}\right)$ e os valores para o Mg estiveram acima da faixa de suficiência (2,5$3,5 \mathrm{~g} \mathrm{~kg}^{-1}$ ), preconizada por MALAVOLTA et al. (1997) para a mamoneira.

Quanto ao K, na safra 2005/2006, os dados foram ajustados à função quadrática e não houve diferença entre as fontes (Figura 1). Na safra 2006/2007, não houve efeito dos tratamentos e também não houve diferença entre as fontes (Tabela 1). Nesta safra, a produção de matéria seca foi maior, o que pode ter ocasionado a diluição dos teores de $\mathrm{K}$, à medida que as doses de nitrogênio foram maiores. Em ambas as safras, os valores observados estiveram abaixo da faixa adequada (30-40 $\mathrm{g} \mathrm{kg}^{-1}$ ) preconizada por MALAVOLTA et al. (1997). De acordo com a diagnose foliar, a maioria dos nutrientes estiveram dentro da faixa adequada. Esses dados são coerentes, pois os teores no solo foram classificados de médio a alto.

Quanto ao teor de S, observou-se que o aumento das doses de $\mathrm{N}$ na forma de uréia ocasionou decréscimo linear dos teores em ambas as safras (Figura 1), mesmo após ter sido feita a compensação desse nutriente com gesso agrícola. O SA não influenciou nos resultados, por apresentar $22 \%$ de $\mathrm{S}$ em sua composição. $\mathrm{O} \mathrm{N}$ e o $\mathrm{S}$ possuem funções semelhantes, principalmente aquelas relacionadas à síntese de proteína e processos fotossintéticos. Desse modo, segundo BÜLL (1993), o fornecimento inadequado de um desses nutrientes acarretará o desbalanceamento entre ambos. Quando se eleva a dose de N na adubação, é necessário aumentar proporcionalmente a dose de $\mathrm{S}$, a fim de garantir o equilíbrio desses nutrientes na planta (MALAVOLTA, 1986).

A adubação nitrogenada proporcionou incremento na produção de matéria seca em ambas as safras (Figura 2), porém não houve efeito significativo para fontes (Tabela 1). Os dados foram ajustados à função quadrática em ambas as safras. Na safra 2005/ 2006, o máximo acúmulo de matéria seca por planta $(26,5 \mathrm{~g})$ ocorreu com a dose calculada de $71 \mathrm{~kg} \mathrm{ha}^{-1} \mathrm{de}$ N. Na safra 2006/2007, o máximo acúmulo de MS por 


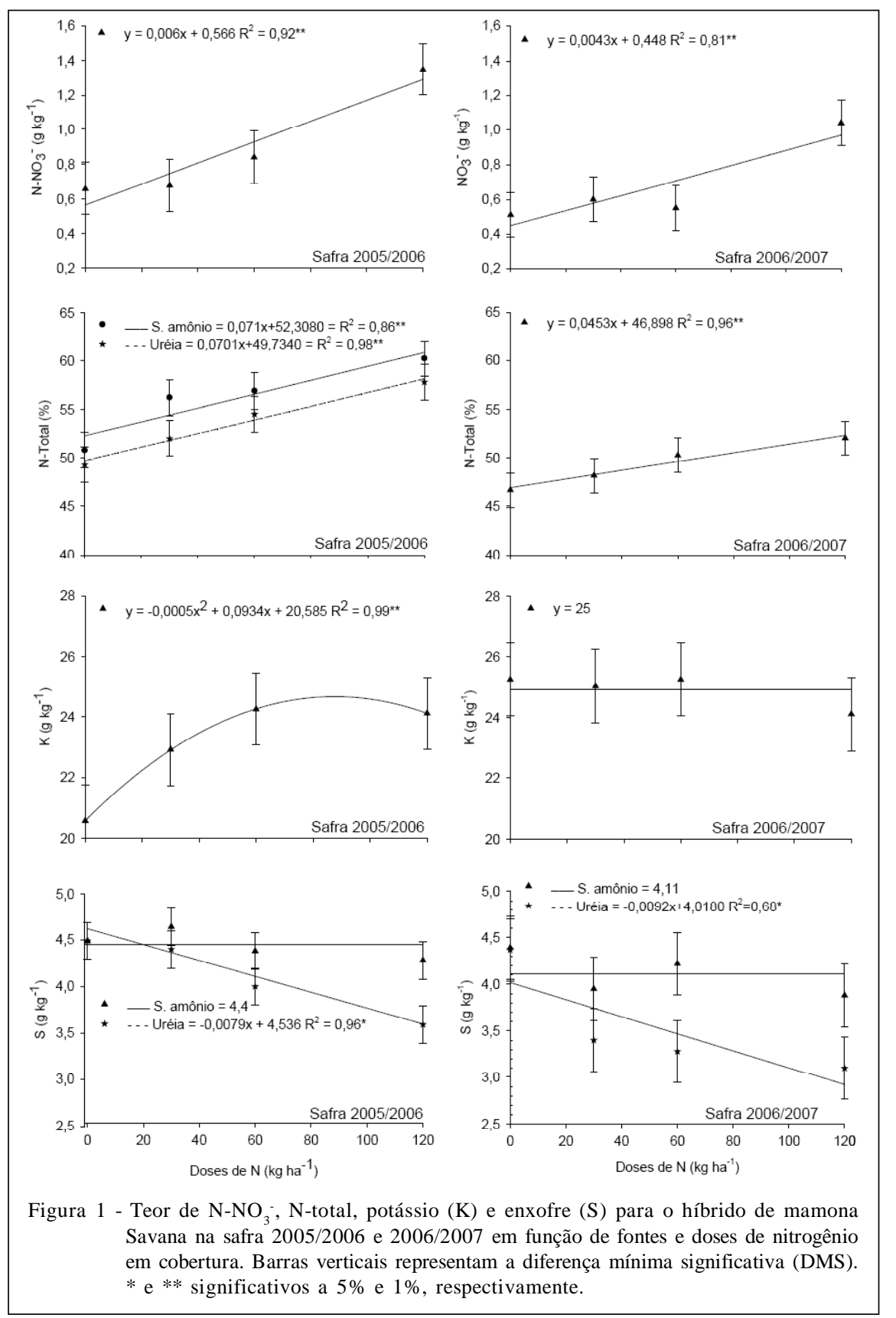

planta (32g) ocorreu com a dose calculada de $133 \mathrm{~kg} \mathrm{ha}^{-1}$ de N. O ajuste quadrático dos dados provavelmente ocorreu devido ao baixo desenvolvimento inicial da cultura e ao florescimento precoce (45 DAE) que foi o momento da coleta das plantas para determinação da matéria seca. De acordo com LAVRES JUNIOR et al. (2005), o N é o nutriente que mais limita o crescimento de híbridos de mamona, na sua ausência a redução de produção da MS foi de $68 \%$.
A população final de plantas não foi influenciada pelas fontes, doses e interações. No entanto, houve efeito de ano (Tabela 2). Quanto ao número de racemos na safra 2005/2006, constatou-se ajuste quadrático dos dados, no entanto, não houve diferença entre as fontes (Figura 2). Na safra 2006/2007, as fontes de $\mathrm{N}$ não interferiram no resultado. Ao avaliar doses de N para o híbrido Sara no sistema plantio direto, SILVA et al. (2007) não constataram alterações no 
Tabela 1 - Matéria seca, nitrato $\left(\mathrm{N}_{-} \mathrm{NO}_{3}{ }^{-}\right)$, amônio $\left(\mathrm{N}-\mathrm{NH}_{4}{ }^{+}\right)$e macronutrientes $(\mathrm{N}, \mathrm{P}, \mathrm{K}, \mathrm{Ca}, \mathrm{Mg}$ e $\mathrm{S})$ da parte aérea do híbrido de mamona Savana em função de fontes e doses de nitrogênio na safra 2005/2006 e 2006/2007.

\begin{tabular}{|c|c|c|c|c|c|c|c|c|c|}
\hline Variáveis & $\mathrm{N}-\mathrm{NO}_{3}{ }^{-}$ & $\mathrm{N}-\mathrm{NH}_{4}{ }^{+}$ & $\mathrm{N}$ & $\mathrm{P}$ & $\mathrm{K}$ & $\mathrm{Ca}$ & $\mathrm{Mg}$ & $\mathrm{S}$ & $\operatorname{MSPA}^{(1)}$ \\
\hline & ------ & 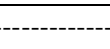 & -- & - & 1 & --- & $-\cdots$ & ----- & -- g planta $^{-1}$-- \\
\hline \multicolumn{10}{|l|}{ Fontes N } \\
\hline S. de amônio & $0,78 \mathrm{a}$ & $1,4 \mathrm{a}$ & $53 a$ & $3,3 \mathrm{a}$ & $24 \mathrm{a}$ & $15 \mathrm{a}$ & $3,8 \mathrm{a}$ & $4,3 a$ & $25 \mathrm{a}^{(2)}$ \\
\hline Uréia & $0,78 \mathrm{a}$ & $1,4 \mathrm{a}$ & $51 b$ & $3,3 \mathrm{a}$ & $24 \mathrm{a}$ & $16 \mathrm{a}$ & $4,0 \mathrm{a}$ & $3,9 b$ & $25 \mathrm{a}$ \\
\hline \multicolumn{10}{|l|}{ Ano (A) } \\
\hline $2005 / 2006$ & $0,88 \mathrm{a}$ & $2,4 \mathrm{a}$ & $55 \mathrm{a}$ & $3,9 \mathrm{a}$ & $23 b$ & $16 a$ & $3,9 \mathrm{a}$ & $4,3 \mathrm{a}$ & $24 b$ \\
\hline $2006 / 2007$ & $0,68 b$ & $0,5 b$ & $49 b$ & $2,7 \mathrm{~b}$ & $25 \mathrm{a}$ & $14 b$ & $3,9 \mathrm{a}$ & $3,8 b$ & $26 a$ \\
\hline Fontes N (F) & NS & NS & $*$ & NS & NS & NS & NS & $* *$ & $\mathrm{NS}^{(3)}$ \\
\hline Doses N (D) & $* *$ & NS & $* *$ & NS & NS & NS & NS & $* *$ & $* *$ \\
\hline Ano (A) & $* *$ & $* *$ & $* *$ & $* *$ & $*$ & $* *$ & NS & $* *$ & $*$ \\
\hline$F \times D$ & NS & NS & NS & NS & NS & NS & NS & NS & NS \\
\hline $\mathrm{F} \times \mathrm{A}$ & NS & NS & NS & NS & NS & NS & NS & NS & NS \\
\hline $\mathrm{D} \times \mathrm{A}$ & NS & NS & NS & NS & NS & NS & NS & NS & $* *$ \\
\hline$F \times D \times A$ & NS & NS & NS & NS & NS & NS & NS & NS & NS \\
\hline
\end{tabular}

${ }^{(1)}$ MSPA- matéria seca da parte aérea. ${ }^{(2)}$ Médias seguidas pela mesma letra, na coluna, não diferem entre si a 5\%, pelo teste LSD. ${ }^{(3)}$ NS, * e **: não-significativo e significativo a 5 e $1 \%$, respectivamente, pelo teste $\mathrm{F}$.

número de racemos, porém, nesse caso, a cultura antecessora foi o feijão.

O número de frutos por racemos não diferiu entre as fontes na safra 2005/2006, mas foi afetado pelas doses de N (Tabela 2). Os dados médios das duas fontes foram ajustados à função quadrática (Figura 2). O maior número de frutos por racemo (27) ocorreu com a dose calculada de $85 \mathrm{~kg} \mathrm{ha}^{-1}$ de N. Na safra 2006/2007, não houve efeito dos tratamentos e também não houve diferenças em função das fontes de nitrogênio. Utilizando a fonte uréia para híbrido de mamona Sara (no sistema plantio direto), SILVA et al. (2007) observaram ajuste quadrático dos dados para o número de frutos por racemos. Neste trabalho, a maior quantidade de frutos foi obtida com a dose calculada de $80 \mathrm{~kg} \mathrm{ha}^{-1} \mathrm{de} \mathrm{N}$.

O número de grãos por fruto foi sempre três, independente da dose e fonte de N. Esse componente de produção não foi influenciado pelo ambiente, ou por fatores exógenos, pois parece ser uma característica de alta herdabilidade.

O peso de 100 grãos foi influenciado pelas doses de $\mathrm{N}$, porém não houve diferenças entre as fontes. Os dados foram ajustados à função quadrática (Figura 2). Na safra 2005/2006, o maior peso de 100 grãos (40g) ocorreu com a dose calculada de $110 \mathrm{~kg} \mathrm{ha}^{-1} \mathrm{de} \mathrm{N}$ (média das duas fontes). Na safra 2006/2007, o maior peso de 100 grãos (37g) ocorreu com a dose calculada de $102 \mathrm{~kg}$ $\mathrm{ha}^{-1}$ de $\mathrm{N}$. Utilizando como fonte de $\mathrm{N}$ a uréia, MEIRA et al. (2005) não observaram efeito desse nutriente no peso de 100 grãos do feijoeiro no SPD.

A produtividade de grãos, na safra 2005/ 2006, foi afetada pelas doses de $\mathrm{N}$ e os dados foram ajustados à função quadrática (Figura 2). A máxima produtividade $\left(2.157 \mathrm{~kg} \mathrm{ha}^{-1}\right)$ foi obtida com a dose calculada de $84 \mathrm{~kg} \mathrm{ha}^{-1}$ de $\mathrm{N}$. O ajuste quadrático dos dados ocorreu devido ao número de frutos por racemo e o peso de 100 grãos apresentarem o mesmo comportamento. Na safra 2006/2007, as doses de N influenciaram na produtividade de grãos, e os dados tiveram resultado linear. Ajuste quadrático dos dados também foi observado por SILVA et al. (2007). O ponto de máxima produtividade foi obtido com de $80 \mathrm{~kg} \mathrm{ha}^{-1}$ de $\mathrm{N}$ em cobertura para o híbrido de mamona Sara.

A expressiva diferença de produtividade observada entre a testemunha da safra 2005/2006 e os tratamentos com nitrogênio pode estar relacionada à cultura antecessora. Na safra 2005/2006, o híbrido de mamona foi semeado após a cultura do milho, enquanto que, na safra seguinte, foi semeado sobre a cultura da aveia. De acordo com dados de TORRES et al. (2005), a relação C/N da aveia foi de 30. Segundo GONÇALVES \& CERETTA (1999), no SPD, existe menor disponibilidade de $\mathrm{N}$ às plantas, devido à imobilização, principalmente quando os resíduos culturais possuem alta relação $\mathrm{C} / \mathrm{N}$, como é o caso do milho. Embora não tenha havido diferenças entre as fontes de $\mathrm{N}$, é 


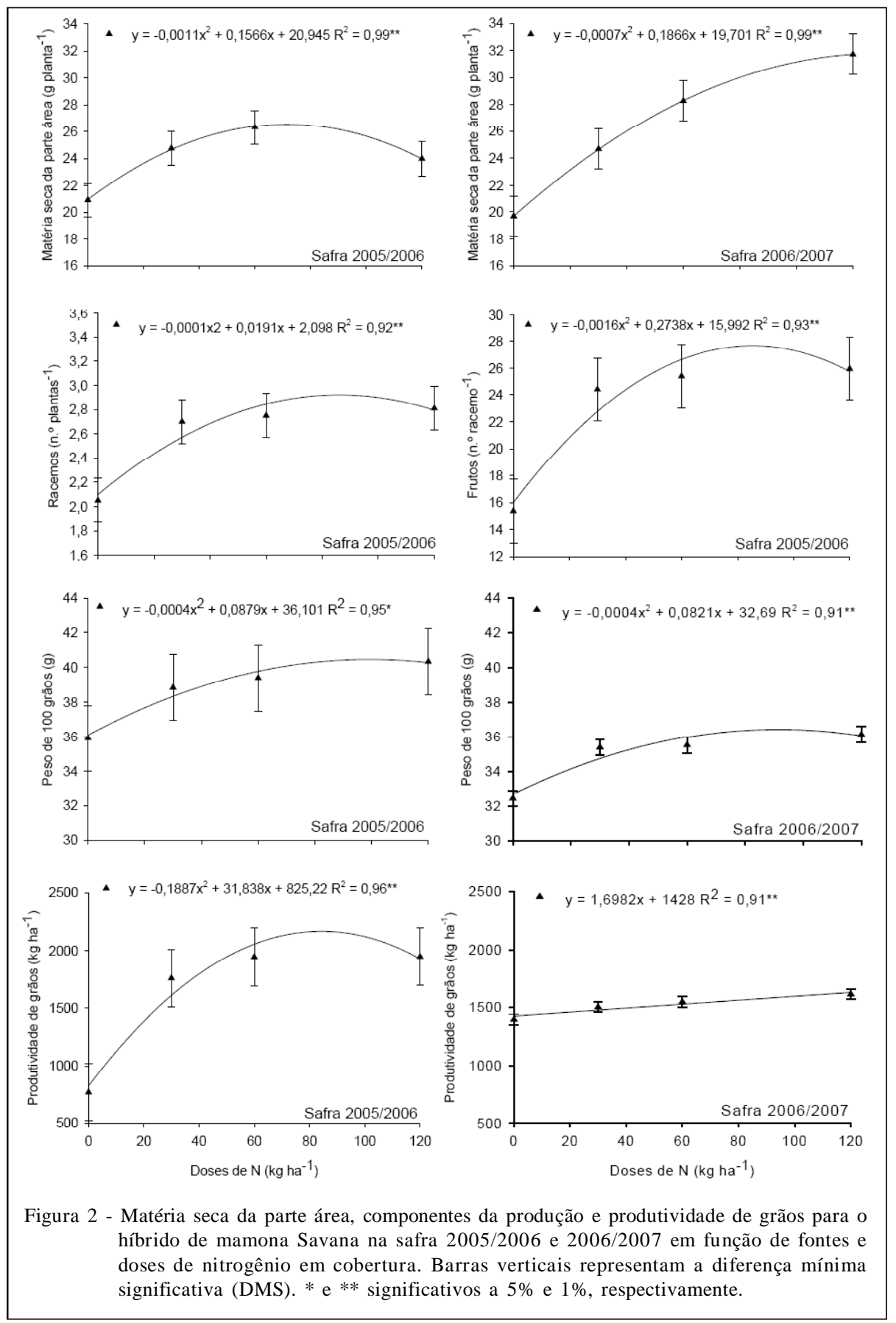

importante destacar que o custo por unidade de $\mathrm{N}(\mathrm{kg})$ do sulfato de amônio é $25 \%$ superior à uréia. Nesse caso, a utilização da uréia seria mais interessante do ponto de vista econômico. No entanto, recomenda-se que sejam seguidos critérios para evitar perdas por volatilização, dentre os quais não aplicar o fertilizante sem que o solo esteja com a umidade adequada.

\section{CONCLUSÃO}

A adubação nitrogenada de cobertura promoveu aumento de produtividade ao híbrido de mamona Savana cultivado no sistema plantio direto. A produtividade de grãos não diferiu entre as fontes de $\mathrm{N}$ utilizadas. A dose média de $\mathrm{N}$ que proporcionou a 
Tabela 2 - Componentes de produção e produtividade de grãos do híbrido de mamona Savana em função de fontes e doses de nitrogênio na safra 2005/2006 e 2006/2007.

\begin{tabular}{|c|c|c|c|c|c|}
\hline Variáveis & $\begin{array}{c}\text { P. final } \\
\text { Plantas ha-1 }\end{array}$ & $\begin{array}{c}\text { Racemos } \\
\text { Número planta-1 }\end{array}$ & $\begin{array}{c}\text { Frutos } \\
\text { Número Racemo }^{-1}\end{array}$ & $\begin{array}{c}\text { Peso } \\
100 \text { grãos }\end{array}$ & $\begin{array}{c}\text { Produtividade } \\
\mathrm{kg} \mathrm{ha}^{-1}\end{array}$ \\
\hline \multicolumn{6}{|l|}{ Fontes N } \\
\hline S. amônio & $24.530 \mathrm{a}^{(1)}$ & $3,0 \mathrm{a}$ & $22 \mathrm{a}$ & $37 \mathrm{a}$ & $1.546 \mathrm{a}$ \\
\hline Uréia & $24.520 \mathrm{a}$ & $3,0 \mathrm{a}$ & $23 a$ & $37 \mathrm{a}$ & $1.576 \mathrm{a}$ \\
\hline \multicolumn{6}{|l|}{ Ano (A) } \\
\hline $2005 / 2006$ & $25.000 \mathrm{a}$ & $2,6 b$ & $23 a$ & $38 \mathrm{a}$ & $1.605 \mathrm{a}$ \\
\hline $2006 / 2007$ & $24.050 \mathrm{~b}$ & $3,0 \mathrm{a}$ & $22 \mathrm{a}$ & $35 b$ & $1.517 \mathrm{a}$ \\
\hline Fontes N (F) & $\mathrm{NS}^{(2)}$ & NS & NS & NS & NS \\
\hline Doses N (D) & NS & $* *$ & $* *$ & $* *$ & $* *$ \\
\hline Ano (A) & $* *$ & $* *$ & NS & $* *$ & NS \\
\hline$F \times D$ & NS & NS & NS & NS & NS \\
\hline $\mathrm{F} \times \mathrm{A}$ & NS & NS & NS & NS & NS \\
\hline $\mathrm{D} \times \mathrm{A}$ & NS & $* *$ & $* *$ & NS & $* *$ \\
\hline F $x D \times A$ & NS & NS & NS & NS & NS \\
\hline
\end{tabular}

${ }^{(1)}$ Médias seguidas pela mesma letra, na coluna, não diferem entre si a 5\%, pelo teste LSD. ${ }^{(2)}$

$\mathrm{NS}, *$ e **: não-significativo e significativo a 5 e $1 \%$, respectivamente, pelo teste $\mathrm{F}$.

maior produtividade de grãos foi de $88 \mathrm{~kg} \mathrm{ha}^{-1}$ na safra 2005/2006 e 100kg ha ${ }^{-1}$ na safra 2006/2007.

\section{AGRADECIMENTOS}

À FAPESP, pelo financiamento da pesquisa, e ao $\mathrm{CNPq}$, pela bolsa de produtividade em pesquisa concedida ao terceiro autor.

\section{REFERÊNCIAS}

ANJOS, J.T.; TEDESCO, M.J. Volatilização de amônia proveniente de dois fertilizantes nitrogenados aplicados em solos cultivados. Científica, v.4, p.49-55, 1976.

AZEVEDO, D.M.P. et al. Recomendações técnicas para o cultivo da mamona (Ricinus communis L.) no Brasil. Campina Grande: Embrapa Algodão, 1997. 52p. (Circular Técnica, 25).

AZEVEDO, D.M.P. et al. Manejo cultural. In: AZEVEDO, D.M.P.; LIMA, E.F. (Eds.). O agronegócio da mamona no Brasil. Brasília: Embrapa Informação Tecnológica, 2001. p.121-160.

BARBOSA FILHO, M.P.; SILVA, O.F. Adubação de cobertura do feijoeiro irrigado com uréia fertilizante em plantio direto: um ótimo negócio. Informações Agronômicas, v.93, p.1-5, 2001.

BELTRÃO, N.E.M. Informações sobre o biodiesel, em especial feito com óleo de mamona. Campina Grande: Ministério da Agricultura, Pecuária e Abastecimento, 2003. 3p.

BULL, L.T. Nutrição mineral do milho. In: BULL, L.T.; CANTARELlA, H. Cultura do milho: faores que afetam a produtividade. Piracicaba: Potafos, 1993. p.63-122.
D'ANDRÉA, A.F. et al. Estoque de carbono e nitrogênio e formas de nitrogênio mineral em um solo submetido a diferentes sistemas de manejo. Pesquisa Agropecuária Brasileira, v.39, p.179-186, 2004. Disponível em: <http://www.scielo.br/scielo.php?pid=S0100204X200 $4000200012 \&$ script=sci_arttext\&tlng=pt>. Acesso em: 10 jul. 2009. doi: 10.1590/S0100-204X2004000200012.

EMBRAPA. Sistema brasileiro de classificação de solos. 2.ed. Rio de Janeiro: Embrapa Solos, 2006. 306p.

FAGERIA, N.K. et al. Maximização da eficiência de produção das culturas. Brasília: Embrapa-SCT/EmbrapaCNPAF, 1999. 294p.

GONÇALVES, C.N.; CERETTA, C.A. Plantas de cobertura de solo antecedendo o milho e seu efeito sobre o carbono orgânico do solo, sob plantio direto. Revista Brasileira de Ciência do Solo, v.23, p.307-313, 1999. Disponível em: <http:// sbcs.solos.ufv.br/solos/revistas/v23n2a15.pdf>. Acesso em: 10 jul. 2009.

HEINRICHS, R. et al. Cultivo consorciado de aveia e ervilhaça: relação $\mathrm{C} / \mathrm{N}$ da fitomassa e produtividade do milho em sucessão. Revista Brasileira de Ciência do Solo, v.25, p.331-340, 2001. Disponível em: <http://sbcs.solos.ufv.br/solos/revistas>. Acesso em: 10 jul. 2009.

LAVRES JUNIOR, J. et al. Deficiências de macronutrientes no estado nutricional da mamoneira cultivar 'Íris'. Pesquisa Agropecuária Brasileira, v.40, p.145-151, 2005. Disponível em: <http://www.scielo.br/scielo.php?pid=S0100204X2005000 $200007 \&$ script $=$ sci_arttext $\&$ tlng $=\mathrm{pt}>$. Acesso em: $10 \mathrm{jul}$. 2009. doi: 10.1590/S0100-204X2005000200007.

MALAVOLTA, E. et al. Avaliação do estado nutricional de plantas: princípios e aplicações. 2.ed. Piracicaba: Potafos, 1997. 319p. 
MALAVOLTA, E. O enxofre na agricultura, situação atual, perspectivas e sugestões. In: SIMPÓSIO: $\mathrm{P}, \mathrm{Ca}, \mathrm{Mg}, \mathrm{S}$, MICRONUTRIENTES: SITUAÇÃO ATUAL E PERSPECTIVAS NA AGRICULTURA, 1984, São Paulo, SP. Anais... São Paulo: Manah, 1986. p.101-108.

MEIRA F.A. et al. Doses e épocas de aplicação de nitrogênio no feijoeiro irrigado cultivado em plantio direto. Pesquisa Agropecuária Brasileira, v.40, p.383-388, 2005. Disponível em: <http:// www.scielo.br/scielo.php?script $=$ sci_arttext\&pid $=$ S0 100 204X2005000400010>. Acesso em: 15 jul. 2009. doi: 10.1590/ S0100-204X2005000400010.

NAKAGAWA, J. Marcha de absorção de nitrogênio, fósforo, potássio, cálcio e magnésio e efeitos da adubação NPK na mamoneira (Ricinus communis L.), cultivada em Latossolo Vermelho Amarelo fase arenosa. 1971. 66f. Tese (Doutorado em Ciências /Agrotecnia e Geologia) Faculdade de Ciências Médicas e Biológicas de Botucatu, Unesp. Botucatu, SP.

PEUKE, A.D. et al. The uptake and flow of $\mathrm{C}, \mathrm{N}$ and ions between roots and shoots in Ricinus communis L. IV. Flow and metabolism of inorganic nitrogen and malate depending on nitrogen nutrition and salt treatment. Journal of Experimental Botany, v.47, p.377-385, 1996. Disponível em: <http://jxb.oxfordjournals.org/cgi/reprint/47/3/377>. Acesso em: 15 jul. 2009.

SANTOS, A.C.M. et al. Deficiência de nitrogênio na mamona (Ricinus communis L.): descrição e efeito sobre o crescimento e a produção da cultura, Campina Grande, PB, 2004. In: CONGRESSO BRASILEIRO DE MAMONA, 2004, Campina Grande, PA. Anais... Campina Grande: Embrapa, 2004. 1 CD-ROM.

SAVY FILHO, A. Mamona. In: RAIJ, B. et al. Recomendações de adubação e calagem para o Estado de São Paulo. Campinas: IAC, 1997. p.201. (Boletim 100).

SILVA, T.R.B. et al. Adubação nitrogenada em cobertura na cultura da mamona em plantio direto. Pesquisa Agropecuária Brasileira, v.42, p.1357-1359, 2007. Disponível em: <http:/ /www.scielo.br/scielo.php?pid=S0100204X20070009 00018\&script=sci_abstract\&tlng=pt $>$. Acesso em: 15 jul. 2009. doi: 10.1590/S0100-204X2007000900018.

SOUZA, S.R.; FERNANDES, M.S. Nitrogênio. In: FERNANDES, M.S. Nutrição mineral de plantas. Viçosa: Sociedade Brasileira de Ciência do Solo, 2006. p.215-252.

TEDESCO, M.J. et al. Análises de solo, plantas e outros materiais. Porto Alegre: Universidade Federal do Rio Grande do Sul, 1985. 188p

TORRES, J.L.R. et al. Decomposição e liberação de nitrogênio de resíduos culturais de plantas de cobertura em um solo de cerrado. Revista Brasileira de Ciência do Solo, v.29, p.609618, 2005. Disponível em: <http://www.scielo.br/pdf/\%0D/rbcs/ v29n4/26109.pdf $>$. Acesso em 15 jul. 2009. doi: 10.1590/ S0100-06832005000400013. 